\title{
Flow Analysis of Fresh Vegetable Box Based on Multiporosity Material
}

\author{
${ }^{\mathrm{a}}$ Yu-Zhou Lou, ${ }^{\mathrm{b}}$ Yun-De Shen, ${ }^{\mathrm{c}}$ Hai-Dong Qian, ${ }^{\mathrm{d}}$ Bin Sun, ${ }^{\mathrm{e}}$ Zhen-Zhe Li*, ${ }^{\mathrm{f}}$ Kai-Bin Cao \\ College of Mechanical and Electrical Engineering Wenzhou University Wenzhou Higher Education Park, \\ Zhejiang, P.R. China
}

\begin{abstract}
Fresh vegetable box is a box including a gas control device, uses of the principle of controlled atmosphere to keep fresh vegetable effect. In the preservation process, the fresh vegetable box can not be so easy to obtain uniform velocity field because the parameters of the box have different effects, and it will affect final preservation effect of fresh vegetable box. In this paper, a fresh vegetable box based on multiporosity material was recommended. 5 different cases were candidated and analyzed for investigating the effect of the property of the multiporosity material. The analysis results show that the property has an important effect to final velocity uniformity. The developed product and method can be used to develop a high performance fresh vegetable box.
\end{abstract}

Index Terms: Fresh Vegetable Box; Multiporosity; Numerical Simulation; Computational Fluid Dynamics

(C) 2012 Published by MECS Publisher. Selection and/or peer review under responsibility of the International Conference on E-Business System and Education Technology

\section{Introduction}

Fresh vegetable box can be defined as an original box including a gas control device, disperses the gas to the box uniformly, so as to achieve the purpose of freshing vegetables [1-3].

Optimization methods of the fresh vegetables and its examination of the characteristics have been very mature, but the problem about the optimization of the fresh vegetable box has not been launched widely. In the preservation process, the fresh vegetable box can not be so easy to obtain uniform velocity field because the parameters of the box have different effects, and it will affect final preservation effect of fresh vegetable box [13].

In this paper, the effect of a property of multiporosity material to velocity uniformity of a fresh vegetable box was investigated. At first, a fresh vegetable box based on multiporosity material was recommended. In the following step, 5 different cases were analyzed and discussed. 


\section{Description of analysis model}

A fresh vegetable box based on multiporosity material was recommended for developing a high performance fresh vegetable box having a uniform velocity field. The size of the box was $1.8 \mathrm{~m} \times 1.25 \mathrm{~m} \times 1.2 \mathrm{~m}$. The distance between the multiporosity material layer and bottom surface of the box was $0.1 \mathrm{~m}$, and the thickness of the multiporosity material layer was $0.01 \mathrm{~m}$ as shown in Fig. 1 . The height of the considering domain was just $0.2 \mathrm{~m}$ from bottom surface of the box for simplicity, and upper computational domain was for considering the convergence of computation.

In this study, a commercial CFD (computational fluid dynamics) code - FLUENT was used to simulate the incompressible flow model which was based on finide volume method. Finite volume method is one of the methods for solving partial difference equations [4-6], and $\mathrm{k}-\varepsilon$ turbulence model was used in this simulation.

The objective of this study was that the surface $0.2 \mathrm{~m}$ away from the bottom surface of the box has uniform velocity of $0.01 \mathrm{~m} / \mathrm{s}$. So, the inlet velocity can be calculated using the velocity of $0.01 \mathrm{~m} / \mathrm{s}$ and the area of the inlet. The boundary condition of outlet was outflow condition, and the other boundaries were wall boundary conditions.

5 different analysis cases which having dirrerent C2 shown in (1) were considered in this study, and the selected values were shown in Table 1.

Figure 1. Computational model

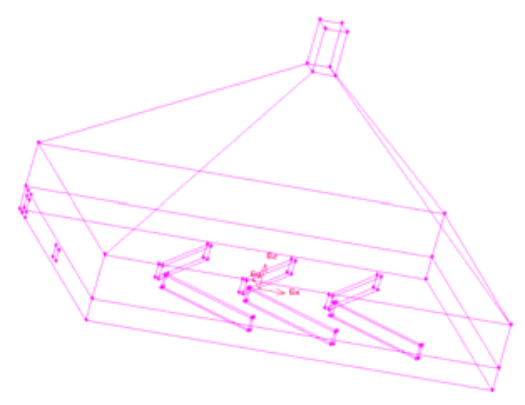

Table 1. Analysis cases

\begin{tabular}{c|c}
\hline Item & $\mathrm{C} 2$ \\
\hline Case 1 & $2.222 \mathrm{e} 8$ \\
\hline Case 2 & $2.824 \mathrm{e} 8$ \\
\hline Case 3 & $2.876 \mathrm{e} 8$ \\
\hline Case 4 & $3.384 \mathrm{e} 8$ \\
\hline Case 5 & $3.173 \mathrm{e} 8$ \\
\hline
\end{tabular}

$$
\Delta p=-\left(\frac{\mu}{\alpha} v+\frac{1}{2} C_{2} \rho v^{2}\right) \Delta m
$$




\section{3. analysis results}

Table 2 shows the minimum velocity, the maximum velocity and the velocity difference on the surface described in chapter 2, and Fig. 2 shows the velocity distribution of the surface. As shown in Table 2 and Fig. 2, the velocity uniformity have been changed when adjusting the property of the multiporosity material. So, the conclusion can be obtained that the property of the multiporosity material has an important effect to velocity uniformity of the fresh vegetable box. Also, it can be found out that the pressure field can be modified by investigating the cases in Fig. 3. In a word, it means that optimization should be carried out for improving the performance of the fresh vegetable box $[7,8]$.

Table 2. Analysis result of each case

\begin{tabular}{c|c|c|c}
\hline Item & $\operatorname{Min}(\mathrm{m} / \mathrm{s})$ & $\operatorname{Max}(\mathrm{m} / \mathrm{s})$ & Difference $(\mathrm{m} / \mathrm{s})$ \\
\hline Case 1 & -1.51514330 & 0.98369271 & 2.49883601 \\
\hline Case 2 & -2.46129180 & 1.46866610 & 3.92995790 \\
\hline Case 3 & -1.15333160 & 0.66521871 & 1.81855031 \\
\hline Case 4 & -0.82490879 & 0.41311473 & 1.23802352 \\
\hline Case 5 & -0.55423987 & 0.34427935 & 0.89851922 \\
\hline
\end{tabular}

\section{Conclusions}

A fresh vegetable box based on multiporosity material was recommended. Based on a commercial CFD code - FLUENT, 5 different cases were analyzed and discussed. The analysis results show that the property of multiporosity material has an important effect to velocity uniformity of the fresh vegetable box. Using optimization, the developed product and method can be widely used to develop a high performance fresh vegetable box.

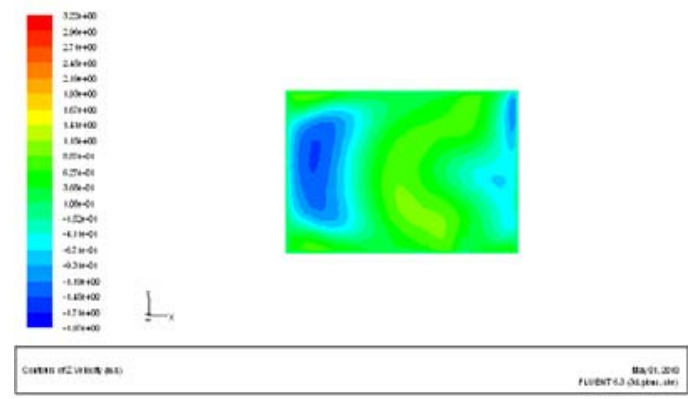

Figure 2(a). Velocity distribution(Case 1) 


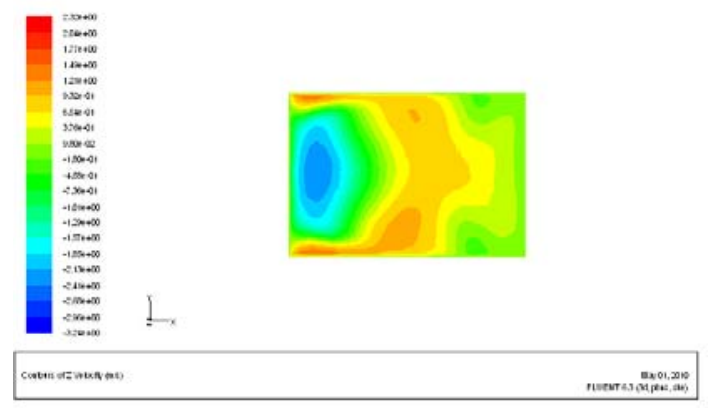

Figure 2(b). Velocity distribution(Case 2)

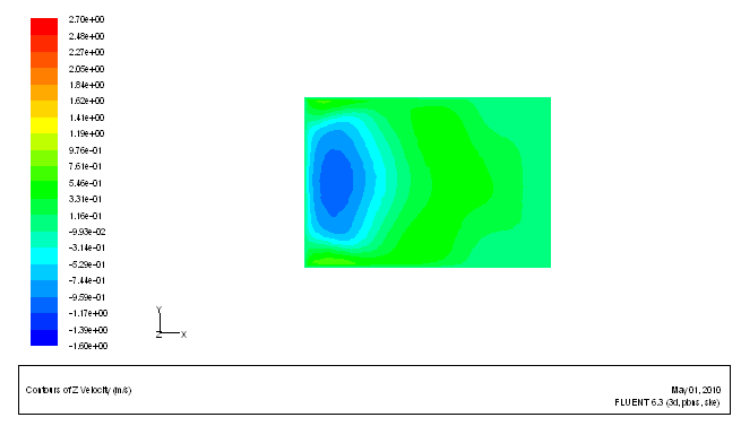

Figure 2(c). Velocity distribution(Case 3)

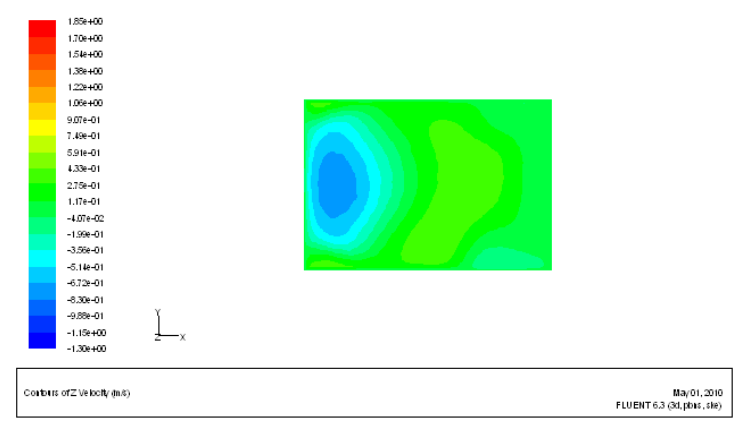

Figure 2(d). Velocity distribution(Case 4) 


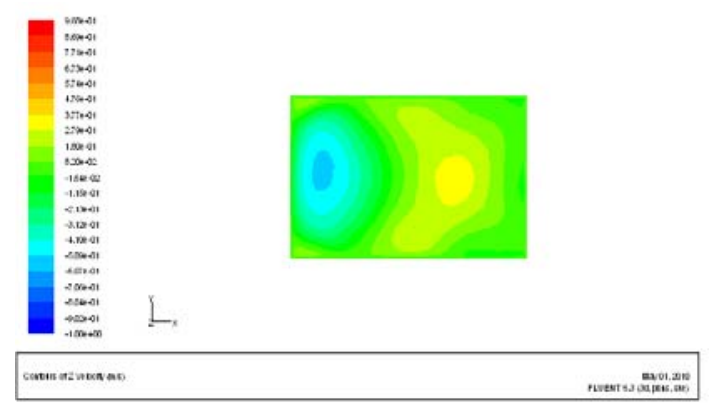

Figure 2(e). Velocity distribution(Case 5)

\section{References}

[1] J. Xie et al., "Method and technology of preserving fresh vegetables," Refrigeration Technology(in Chinese), No. 1, pp. 6-9, 2005.

[2] F. Lin et al., "The research on fluits and vegetables CA storage technology," Refrigeration(in Chinese), Vol. 65, No. 4, pp. 14-17, 1998.

[3] M. L. Kang et al., "Research progress in the theory and technology of hypobaric storage," Food and Mechanics(in Chinese), Vol. 82, pp. 9-10, 2001.

[4] Y. S. Lee, T. J. Kang and J. K. Lee, "A study on heat transfer through plain woven fabric. An approach through finite difference method," Journal of the Korean Fiber Society, Vol. 28, No. 9, pp. 707-714, 1991.

[5] J. E. Oh, C. H. Lee, H. J. Sim, H. J. Lee, S. H. Kim and J. Y. Lee, "Development of a system for diagnosing faults in rotating machinery using vibration signals," International Journal of Precision Engineering and Manufacturing, Vol. 8, No. 3, pp. 54-59, 2007.

[6] M. Sahin and H. J. Wilson, "A semi-staggered dilation-free finite volume method for the numerical solution of viscoelastic fluid flows on all-hexahedral elements," Journal of Non-Newtonian Fluid Mechanics, Vol. 147, No. 1-2, pp. 79-91, 2007.

[7] J. S. Arora, "Introduction to optimum design," McGraw-Hill, $2^{\text {nd }}$ Edition, 2001.

[8] Z. Z. Li, Y. D. Shen, K. S. Heo, J. W. Lee, S. Y. Seol, Y. H. Byun and C. J. Lee, "Feasible optimal design of high temperature vacuum furnace using experiences and thermal analysis database," Journal of Thermal Science and Technology, Vol. 2, No. 1, pp. 123-133, 2007.

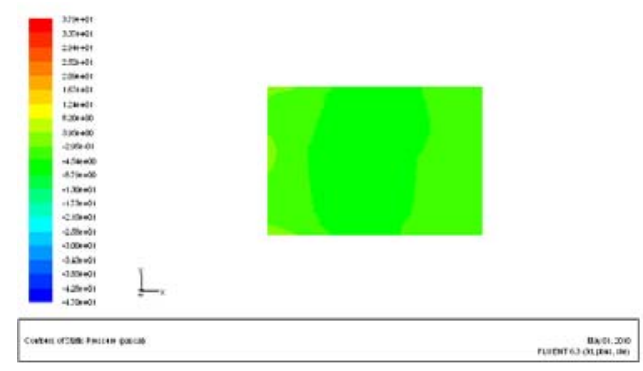

Figure 3(a). Distribution of pressure(Case 1) 


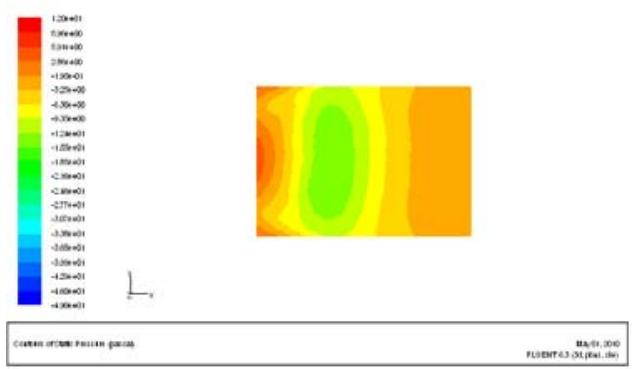

Figure 3(b). Distribution of pressure(Case 2)

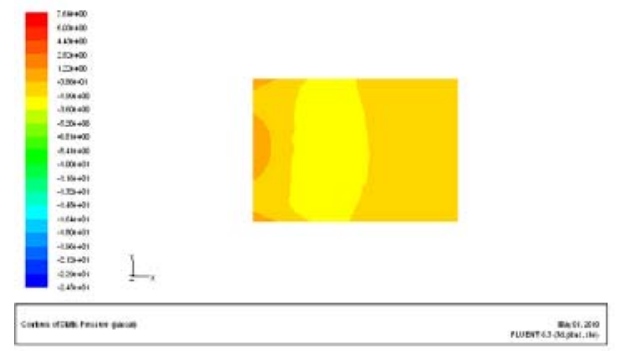

Figure 3(c). Distribution of pressure(Case 3)

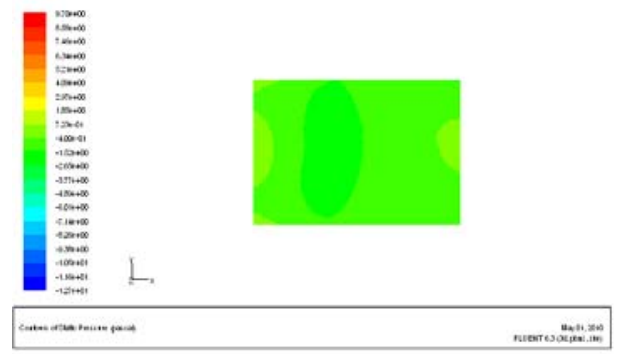

Figure 3(d). Distribution of pressure(Case 4)

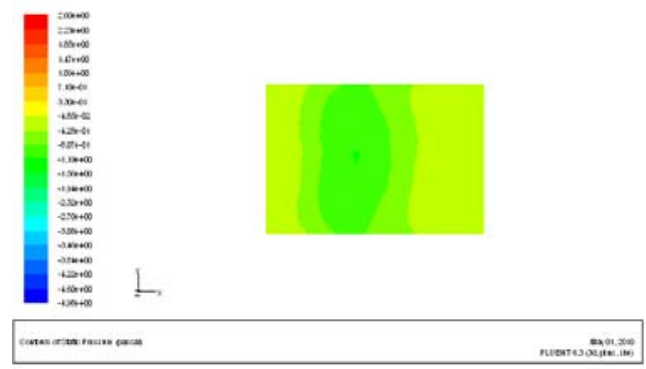

Figure 3(e). Distribution of pressure(Case 5) 